\title{
Comparison of Mechanical Behaviour of Carbon and Glass Fiber Reinforced Epoxy Composites
}

\author{
N. Ozsoy*, A. MimaroĞLu, M. Ozsoy, M.I. Ozsoy \\ Sakarya University, Faculty of Engineering, Mechanical Engineering Department, Serdivan/Sakarya, Turkey \\ An experimental study has been carried out to investigate tensile and bending properties of carbon fiber \\ (CFRE) and glass fiber-reinforced (GFRE) epoxy composites. Three different fiber orientations were applied, $0^{\circ}$, \\ $90^{\circ}$ and $\left[0^{\circ}, 90^{\circ}\right]$. The laminates were obtained by manual lay-up process. The samples were evaluated by tensile \\ tests according to the ASTM D3039 and bending tests according to the ASTM D790. Experimental results showed \\ that maximum tensile strengths were observed at $0^{\circ}$ fiber direction for the both CFRE and GFRE composites. \\ With respect to their tension properties, the CFRE samples had better performance than the GFRE samples, \\ except for the $90^{\circ}$ orientation. Three point bending tests proved that in all orientations CFRE composites had \\ better performance, compared to GFRE composites.
}

DOI: $10.12693 /$ APhysPolA.127.1032

PACS: 81.05.Qk, 81.70.Bt

\section{Introduction}

Many fiber reinforced composite materials offer a combination of strength and modulus that are either comparable to, or better than many traditional metallic materials. Because of their low specific weight, the strengthweight ratios of these composite materials are markedly superior to those of metallic materials [1].

Composite materials based on polymeric matrix are often used over the past decades in aircraft, aerospace structures, automotive and petrochemical industries. Composite products such as pressure vessels, gas pipes, containers and aircraft components became popular and acceptable by most of the engineers and users. Static and dynamic mechanical loading and also the temperature behavior have to be taken into consideration for the design of composite structures [2].

Many researchers have performed tensile tests at different conditions, like strain rates, temperatures and fiber orientations. In these works thermoplastics are commonly used as the matrix. There are a few experiments in which thermosets are used as the matrix.

The change in the fiber orientation with respect to the tensile axis showed a significant difference in tensile strength. This difference shows that the axial tensile strength is very sensitive to the fiber alignment with respect to the external load. This anisotropic mechanical behavior of the material is explained by the fiber orientations effecting the load sharing mechanism [3].

Shokrieh and Omidi performed experiments to find tension behavior of unidirectional glass/epoxy composites under different strain rates. Their experimental results showed a significant increase of the tensile strength by increasing the strain rate. They reported that the

\footnotetext{
*corresponding author; e-mail: nerken@sakarya.edu.tr
}

tensile modulus and strain to failure were also observed to increase slightly by increasing the strain rate [4].

Reis et al. performed tensile tests at different strain rates and temperatures in glass fiber reinforced polymer (GFRP). They observed that strain rate strongly affects the ultimate tensile strength $\left(\sigma_{u}\right)$ and that modulus of elasticity was almost insensitive to it, while temperature only influenced the modulus [2].

Paiva et al. manufactured four different laminate families (F155/PW, F155/HS, F584/PW and F584/HS) using pre-impregnated materials (prepregs) based on F155TM and F584TM epoxy resins reinforced with carbon fiber fabric with Plain Weave (PW) and Eight Harness Satin (8HS) styles. They evaluated samples by tensile tests according to the ASTM D3039. They observed that the F584/PW laminates presented the highest values of tensile strength [5].

In general, the properties of a fiber reinforced composite depend strongly on the direction of measurement. For example, the tensile strength and modulus of unidirectionally oriented fiber-reinforced laminates are maximal when these properties are measured in the longitudinal direction of fibers [1].

In this work, rectangular specimens of polymeric composites with end-tabs in accordance to ASTM D3039 [6] were used. Generally, rectangular specimens are required for the composite material characterization, because the "dog-bone" type tend to split in the region where the width changes. Still the grips of tension test frame introduce large stress concentration in the specimen. To minimize this effect, tabs with tapered ends must be bonded on each side of the specimen, because the tensile test can cause tension concentration with shear load [4].

\section{Materials and experimental work}

Unidirectional carbon fiber fabric and glass fiber fabric were used as reinforcement material. Table I presents the 
specifications of the fabrics. Composites were manufactured by manual lay-up process. Firstly wax was applied to the working surface in order to help to easily separate composite from the surface after the curing. Fabric was cut into squares $40 \times 40 \mathrm{~cm}$. Epoxy resin (MGS L285) was mixed with hardener (HGS L285) in mass ratio of $100 / 40$, as is recommended by the supplier. Composites were cured at room temperature for 24 hours.

Specifications of the fabrics, TABLE I epoxy and hardener.

\begin{tabular}{c|c}
\hline \hline Layer $0^{\circ}$ (E-glass) & 600 tex \\
Layer $90^{\circ}$ (E-glass) & $200 \mathrm{tex}$ \\
Area weight $0^{\circ}$ & $236 \mathrm{~g} / \mathrm{m}^{2}$ \\
Area weight $90^{\circ}$ & $55 \mathrm{~g} / \mathrm{m}^{2}$ \\
Layer $0^{\circ}$ (carbon) & $300 \mathrm{~g} / \mathrm{m}^{2}$ \\
Density(epoxy) & $1.18-1.23 \mathrm{~g} / \mathrm{cm}^{3}$ \\
Viscosity(epoxy) & $600-900 \mathrm{MPa} \mathrm{s}$ \\
Density(hardener) & $0.94-0.97 \mathrm{~g} / \mathrm{cm}^{3}$ \\
Viscosity(hardener) & $50-100 \mathrm{MPa} \mathrm{s}$
\end{tabular}

Tension samples were cut according to the ASTM D3039. Tabs were prepared from aluminum plate and glued to the specimens with epoxy. Tensile tests were conducted with Zwick Roell device at room conditions. Each test was repeated on five samples and the average values were considered. Test speed was $2 \mathrm{~mm} / \mathrm{min}$. Dimensions of tension samples and of the fibers in tension samples are given in Table II.

Tension sample dimensions.

TABLE II

\begin{tabular}{c|c|c|c|c|c}
\hline \hline $\begin{array}{c}\text { Fiber } \\
\text { Orient. }\end{array}$ & $\begin{array}{c}\text { Width } \\
{[\mathrm{mm}]}\end{array}$ & $\begin{array}{c}\text { Length } \\
{[\mathrm{mm}]}\end{array}$ & $\begin{array}{c}\text { Thickn. } \\
{[\mathrm{mm}]}\end{array}$ & $\begin{array}{c}\text { Tab len. } \\
{[\mathrm{mm}]}\end{array}$ & $\begin{array}{c}\text { Tab thickn. } \\
{[\mathrm{mm}]}\end{array}$ \\
\hline $0^{\circ}$ & 15 & 250 & 1 & 56 & 1.5 \\
$90^{\circ}$ & 25 & 175 & 2 & 25 & 1.5 \\
$0^{\circ} / 90^{\circ}$ & 25 & 250 & 2.5 & 56 & 1.5
\end{tabular}

Bending samples were cut according to the ASTM D790 [7]. Each test was repeated on five samples and the average values were considered. The dimensions of samples are given in Table III.

Three point bending sample TABLE III dimensions.

\begin{tabular}{c|c|c|c}
\hline \hline $\begin{array}{c}\text { Fiber } \\
\text { Orientation }\end{array}$ & $\begin{array}{c}\text { Width } \\
{[\mathrm{mm}]}\end{array}$ & $\begin{array}{c}\text { Length } \\
{[\mathrm{mm}]}\end{array}$ & $\begin{array}{c}\text { Thickness } \\
{[\mathrm{mm}]}\end{array}$ \\
\hline $0^{\circ}$ & 12.7 & 56 & 3.2 \\
$90^{\circ}$ & 12.7 & 56 & 3.2 \\
$0^{\circ} / 90^{\circ}$ & 12.7 & 56 & 3.2
\end{tabular}

Epoxy and fibers were weighted separately before composite preparation. After curing the composites were weighted again. According to the results, the weight fractions of fibers were calculated and results are given in Table IV.

The example specimens after testing are shown in Fig. 1. During the tensile tests breaking occurred nearly
Weight fraction (\%) of fibers in tension/three point bending samples.

TABLE IV

\begin{tabular}{c|c|c|c}
\hline \hline Fiber type & $0^{\circ}$ & $90^{\circ}$ & $0^{\circ} / 90^{\circ}$ \\
\hline \multirow{2}{*}{ Carbon } & $40(2$ layers $) /$ & $41(4$ layers $) /$ & $50(5$ layers $) /$ \\
& $50(7$ layers $)$ & $51(7$ layers $)$ & $56.5(7$ layers $)$ \\
\hline \multirow{2}{*}{ Glass } & $40(2$ layers $) /$ & $40(4$ layers $) /$ & $49(5$ layers $) /$ \\
& $52(7$ layers $)$ & $50(7$ layers $)$ & $45(7$ layers $)$
\end{tabular}

in the middle part of the composites. Three point bending tests stopped automatically when the plastic deformation started in the composite.

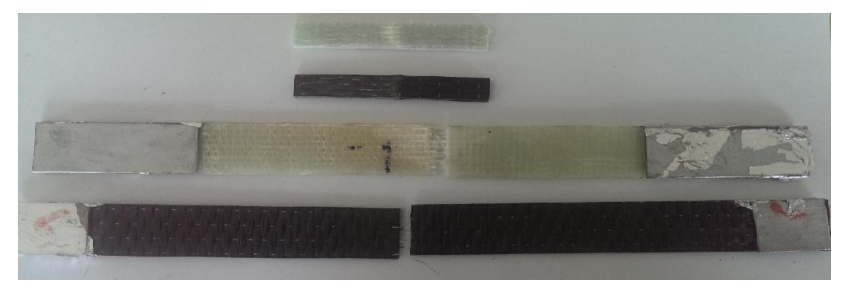

Fig. 1. Three point bending and tensile specimens after tests: a) GFRE bending test sample, b) CFRE bending test sample, c) GFRE tensile test sample, d) CFRE tensile test sample.

\section{Results and discussions}

Tensile strength results of CFRE and GFRE composites are shown in Table $\mathrm{V}$ and Table VI. According to the tensile test results, the maximum strength was seen in $0^{\circ}$ orientation, similar with Gu's work [8], even though these samples had fewer layers than the others, because in this orientation fiber length controls the resistance of the composite. The performance of $0^{\circ} / 90^{\circ}$ orientation samples followed the performance of $0^{\circ}$-samples. The smallest strength result was seen in $90^{\circ}$ orientation.

In CFRE composites the strain results were similar for $0^{\circ}$ and $0^{\circ} / 90^{\circ}$ orientation. Again in $90^{\circ}$ orientation the strain had the lowest results. Maximum strain and elongation at break results are close in $0^{\circ}$ and $0^{\circ} / 90^{\circ}$ oriented CFRE composites. For $90^{\circ}$ orientation, the elongation at break is higher than maximum strain.

Tensile strength of the CFRE composites. TABLE V

\begin{tabular}{c|c|c|c|c}
\hline \hline $\begin{array}{c}\text { Orien- } \\
\text { tation }\end{array}$ & $\begin{array}{c}\text { Breaking } \\
\text { strength } \\
{[\mathrm{MPa}]}\end{array}$ & $\begin{array}{c}\text { Elongation } \\
\text { at break } \\
{[\%]}\end{array}$ & $\begin{array}{c}\text { Maximum } \\
\text { stress } \\
{[\mathrm{MPa}]}\end{array}$ & $\begin{array}{c}\text { Maximum } \\
\text { strain } \\
{[\%]}\end{array}$ \\
\hline 0 & 1270 & 7.3 & 1380 & 7.1 \\
$0 / 90$ & 559 & 7.6 & 568 & 7.7 \\
90 & 2.74 & 5.2 & 10.6 & 3.6
\end{tabular}

Flexural strength of CFRE and GFRE composites is shown in Table VII and Table VIII. In this case composites with $0^{\circ}$ fiber orientation had the highest flexural strengths, similar to tension results. In CFRE composites flexural strengths of $0^{\circ}$ and $90^{\circ}$ samples had similar values. CFRE composites had the same flexural strains $(1.4 \%)$ in all orientations. 
Tensile strength of the GFRE composites. TABLE VI

\begin{tabular}{c|c|c|c|c}
\hline \hline $\begin{array}{c}\text { Orien- } \\
\text { tation }\end{array}$ & $\begin{array}{c}\text { Breaking } \\
\text { strength } \\
{[\mathrm{MPa}]}\end{array}$ & $\begin{array}{c}\text { Elongation } \\
\text { at break } \\
{[\%]}\end{array}$ & $\begin{array}{c}\text { Maximum } \\
\text { stress } \\
{[\mathrm{MPa}]}\end{array}$ & $\begin{array}{c}\text { Maximum } \\
\text { strain } \\
{[\%]}\end{array}$ \\
\hline 0 & 189 & 5.7 & 335 & 5.7 \\
$0 / 90$ & 146 & 3.8 & 158 & 3.8 \\
90 & 38.1 & 6.2 & 43.5 & 6.2
\end{tabular}

Flexural strength of the TABLE VII CFRE composites.

\begin{tabular}{c|c|c}
\hline $\begin{array}{c}\text { Fiber } \\
\text { orientation }\end{array}$ & $\begin{array}{c}\text { Flexural } \\
\text { strength [MPa] }\end{array}$ & $\begin{array}{c}\text { Flexural } \\
\text { strain [\%] }\end{array}$ \\
\hline $0^{\circ}$ & 736 & 1.4 \\
\hline $0^{\circ} / 90^{\circ}$ & 436 & 1.4 \\
\hline $90^{\circ}$ & 720 & 1.4
\end{tabular}

Flexural strength of the TABLE VIII GFRE composites.

\begin{tabular}{c|c|c}
\hline \hline $\begin{array}{c}\text { Fiber } \\
\text { orientation }\end{array}$ & $\begin{array}{c}\text { Flexural } \\
\text { strength [MPa] }\end{array}$ & $\begin{array}{c}\text { Flexural } \\
\text { strain [\%] }\end{array}$ \\
\hline $0^{\circ}$ & 522 & 3.7 \\
$0^{\circ} / 90^{\circ}$ & 424 & 3.8 \\
$90^{\circ}$ & 86 & 2.6
\end{tabular}

According to the GFRE test results, the composites with $90^{\circ}$ orientation had lowest flexural strength. Maximum results were obtained in $0^{\circ}$ orientation. When the composites were compared according to the flexural strength, the CFRE composites had better performances, because carbon fiber, as a single filament, has better mechanical properties, compared to the glass fiber [1].

\section{Conclusions}

The results obtained from the experiments show that tensile and flexural strengths of composites with $0^{\circ}$ of fiber orientation have the best performance. According to the tensile end three point bending test results, the CFRE composites were stronger than the GFRE composites, except for $90^{\circ}$ orientation for tensile test. Tensile strains were higher in CFRE composites, except for $90^{\circ}$ orientation. In all orientations GFRE composites had higher flexural strains than the CFRE ones.

\section{References}

[1] P.K. Mallick, Fiber Reinforced Composites, Markel Dekker, New York, 1993.

[2] J.M.L. Reis, J.L.V. Coelho, A.H. Monteiro, H.S. Da Costa Mattos, Composites: Part B 43, 2041 (2012).

[3] A. Godara, D. Raabe, Composites Science and Technology 67, 2417 (2007).

[4] M.M. Shokrieh, M.J. Omidi, Composite Structures 88, 595 (2009).

[5] J.M. Faulstich De Paiva, S. Mayer, M. Cerqueira Rezende, Materials Research 9, 83 (2006).

[6] ASTM D3039, D3039M-08, Standard Test Method For Tensile Properties of Polymer Matrix Composite Materials, American Society For Testing and Material, 2008.

[7] ASTM D790-10, Standard Test Methods for Flexural Properties of Unreinforced and Reinforced Plastics and Electrical Insulating Materials, American Society for Testing and Material, 2010.

[8] H. Gu, Materials and Design 27, 1086 (2006). 